\section{RIFLE criteria in aortic arch surgery: The further role of surgical subgroup To the Editor:}

I read with great interest the recent article by Arnaoutakis and colleagues ${ }^{1}$ detailing their application of the RIFLE (risk, injury, failure, loss, end stage) criteria in aortic arch surgery. Arnaoutakis and colleagues ${ }^{1}$ clearly demonstrated a significant relationship between degree of renal injury and operative mortality. Their series of 267 patients, however, was heterogeneous with respect to aortic pathology: $35.6 \%$ of the cases $(95 / 267)$ were aortic dissection, with $74.7 \%$ (71/95) being acute and necessitating emergency surgery with deep hypothermic circulatory arrest.

The clinical presentation of acute aortic dissection significantly determines operative risk and mortality, particularly when it is associated with organ ischemia. ${ }^{2}$ Thus this confounding effect of an aortic arch subgroup with distinctive presentations ideally merits a de novo analysis in a large acute aortic dissection series. This goal would require many years to achieve for a single center, however, even a single, high-volume experienced center. As a result, current single-center series, including our own, ${ }^{3}$ have included acute aortic dissection as a subgroup and thus been unable to escape the confounding effects of the mixed aortic arch cohort. ${ }^{3}$ I look forward to future multicenter trials with adequate power to examine the RIFLE criteria in aortic arch surgical cohorts stratified by aortic pathology.

I congratulate Arnaoutakis and colleagues ${ }^{1}$ again on their important contribution. I look forward to their comments about this aspect of trial design.

\section{John G. T. Augoustides, MD, FASE Assistant Professor, Department of Anesthesiology and Critical Care Hospital of the University of Pennsylvania Philadelphia, PA 19104}

\section{References}

1. Arnaoutakis GJ, Bihorac A, Martin TD, Hess PJ, Klodell CT, Ejaz AA, et al. RIFLE criteria for acute kidney injury in aortic arch surgery. J Thorac Cardiovasc Surg. 2007; 134:1554-61.

2. Geirrson A, Szeto WY, Pochettino A, McGarvey, Keane MG, Woo YJ, et al. Significance of malperfusion syndromes prior to contemporary surgical repair for acute type A dissection: outcomes and need for additional revasculari- zations. Eur J Cardiothorac Surg. 2007;32: 255-62.

3. Augoustides JG, Pochettino A, Ochroch EA, Cowie D, Weiner J, Gambone AJ, et al. Renal dysfunction after thoracic aortic surgery requiring deep hypothermic circulatory arrest: definition, incidence, and clinical predictors. J Cardiothorac Vasc Anesth. 2006;20: 673-7.

$$
\text { doi:10.1016/j.jtcvs.2007.12.050 }
$$

\section{Reply to the Editor:}

We appreciate the interest of Dr Augoustides in our article, ${ }^{1}$ and he raises a valid point that the subgroup of patients with acute aortic dissection are at even higher risk for acute kidney injury because of their emergency presentation and variable malperfusion. Patients with acute dissection accounted for 71 of the 97 emergency operations in our series. In the multivariate analysis, emergency surgery (and accordingly acute dissection) was not identified as a risk factor for either acute kidney injury or mortality. As Dr Augoustides noted, however, it would require many years for a single center to examine this question.

The RIFLE criteria provide standardized outcome definitions to study acute kidney injury in patients undergoing arch aortic surgery-a group known to be at significant risk for renal injury. Standardized definitions are the first step if we are to compare outcomes at aortic centers interested in acute kidney injury.

To take the next step-examination of renal protective strategies-we concur with Dr Augoustides that patients should be stratified according to aortic pathology and also that it will take the cooperation of several centers with large aortic experiences. The question then arises, which protective strategies could we study? We and others have been intrigued by the potentially favorable renal effects of nesiritide (Natrecor; Scios Inc, Fremont, Calif). ${ }^{2-5 *}$

It is important to note that even less severe kidney injury after cardiac surgery has been found to be independently associated with in-hospital and long-term mortality. ${ }^{6,7}$ Accordingly, with interest from the center of Dr Augoustides, our own, and others, perhaps it is now time to ask the National Institutes of Health to support a randomized, multicenter trial adequately powered to determine whether nesiritide (or other potential agents) can afford high-risk patients undergoing thoracic aortic surgery protection against acute kidney injury.
Thomas M. Beaver, $M D, M P H$

Azra Bihorac, $M D$

Ahsan A. Ejaz, MD

Division of Cardiovascular Surgery University of Florida

Gainesville, FL 32610

*Disclosure: Authors have received research support from Scios Inc.

\section{References}

1. Arnaoutakis GJ, Bihorac A, Martin TD, Hess PJ Jr, Klodell CT, Ejaz AA, et al. RIFLE criteria for acute kidney injury in aortic arch surgery. J Thorac Cardiovasc Surg. 2007; 134:1554-61.

2. Chen HH, Sundt TM, Cook DJ, Heublein DM, Burnett JC Jr. Low dose nesiritide and the preservation of renal function in patients with renal dysfunction undergoing cardiopulmonary-bypass surgery: a double-blind placebocontrolled pilot study. Circulation. 2007; 116(11 Suppl):I134-8.

3. Beaver TM, Winterstein AG, Shuster JJ, Gerhard T, Martin T, Alexander JA, et al. Effectiveness of nesiritide on dialysis or allcause mortality in patients undergoing cardiothoracic surgery. Clin Cardiol. 2006;29:18-24.

4. Mentzer RM Jr, Oz MC, Sladen RN, Graeve AH, Hebeler RF Jr, Luber JM Jr, et al. Effects of perioperative nesiritide in patients with left ventricular dysfunction undergoing cardiac surgery: the NAPA Trial. J Am Coll Cardiol. 2007;49:716-26.

5. Ejaz AA, Heinig ME, Kazory A, Bihorac A, Hobson CE, Beaver TM. The rise and fall of natriuretic peptides in acute kidney injury: a misunderstood relationship? Rev Cardiovasc Med. 2007;(8 Suppl 5):S32-7.

6. Thakar CV, Worley S, Arrigain S, Yared JP, Paganini EP. Influence of renal dysfunction on mortality after cardiac surgery: modifying effect of preoperative renal function. Kidney Int. 2005;67:1112-9.

7. Loef BG, Epema AH, Smilde TD, Henning RH, Ebels T, Navis G, et al. Immediate postoperative renal function deterioration in cardiac surgical patients predicts in-hospital mortality and long-term survival. $J$ Am Soc Nephrol. 2005;16:195-200.

doi:10.1016/j.jtcvs.2008.03.012

\section{Reply to the Editor:}

I thank Dr Pocar for promoting a discussion about our article and technical proposition. In fact, the juxtaposition of the right free wall over the septum is not new and was applied for the first time by Boer and Boer in 1998 ; $^{1}$ they called it "septal stabilization."

The authors ${ }^{2,3}$ cited by Dr Pocar made an intelligent association of 2 techniques, that is, septal stabilization ${ }^{1}$ and infarction exclusion, ${ }^{4}$ with good results.

In our study, we proposed the juxtaposition of both the right and left free walls over the septum, and this is the originality of the 
procedure. Perhaps it was not clear in our article, but the juxtaposition technique was proposed for anterior ventricular septal rupture, and for this reason we cited the anterior papillary muscle as a reference point to perform the left free wall juxtaposition with a lower risk of excessive left ventricular cavity reduction.

After this technique was applied in 4 patients with good results, posterior ventricular septal rupture was diagnosed in 1 patient with total occlusion of the right coronary artery. This patient had a clear posterior myocardial infarction and posterior ventricular septal rupture.

In this patient, we performed a ventriculotomy in the infarcted area in the posterior wall of the left ventricle. The juxtaposition of the free wall ventricles was done, juxtaposing the posterior free wall of the right ventricle with the posterior free wall of the left ventricle. Cava cannulation was performed, and the right atrium was opened to verify whether any stitch was accidentally in the posterior cusp of the tricuspid valve.

There is nothing controversial about applying the juxtaposition technique to treat posterior ventricular septal rupture. Of course, the anterior papillary muscle is not a reference point in the posterior region.

Although this technique can be used for posterior septal ventricular rupture, the juxtaposition of ventricular walls is more difficult and involves a minor area of juxtaposition.

As I said, we have observed only 1 case of posterior septal rupture, and since then, no patients with septal rupture have undergone operation. The real applicability of this technique for posterior rupture still remains to be defined.

Once again, we emphasize that the innovation of this technique is in the juxtaposition of both the right and left free walls over the septum, promoting the reinforcement of the ventricular septal rupture closure, exclusion of the infarcted area, and safety of ventricular cavity reduction.

I congratulate Dr Pocar and his team for the good surgical results obtained with their technique and thank you for the opportunity to clarify any doubts about our technical proposition.

Luis R. Gerola Gainesville, FL

\section{References}

1. de Boer HD, de Boer WJ. Early repair of postinfarction ventricular septal rupture: infarct exclusion, septal stabilization and left ventricular remodeling. Ann Thorac Surg. 1998;65: 853-4.

2. Marimoto K, Taniguchi I, Miyasaka S, Aoki T, Kato I, Yamaga T. Infarction exclusion technique with transmural sutures for postinfarction ventricular septal rupture. Ann Thorac Cardiovasc Surg. 2004;10:39-41.

3. Bayezid O, Turkay C, Golbasi I. A modified infarct exclusion technique for repair of postinfarction ventricular septal defect. Tex Heart Inst J. 2005;32:299-302.

4. David TE, Dale L, Sun Z. Postinfarction ventricular septal rupture: repair by endocardial patch with infarct exclusion. J Thorac Cardiovasc Surg. 1995;110:1315-22.

doi:10.1016/j.jtcvs.2008.03.015

\section{New technique for postinfarction ventricular septal rupture \\ To the Editor:}

We congratulate Gerola and colleagues ${ }^{1}$ for the outstanding results reported with biventricular free wall juxtaposition to secure postinfarction ventricular septal rupture (VSR) patch repair and would like to add a few comments.

Although not previously described with respect to the left ventricular free wall, right free wall plication over the septum for additional reinforcement of patch repair is conceptually similar and not an entirely new idea. $^{2,3}$ We used the latter approach in a 60-year-old man in whom a modified infarct exclusion operation was performed to repair an anterior VSR with associated oozing-type left ventricular anterior free wall rupture (Figure 1). The patient showed triple-vessel coronary disease and acute left ventricular failure (ejection fraction, 30\%) with cardiogenic shock and was brought to the operating room on mechanical ventilation and intra-aortic balloon counterpulsation 19 hours after the onset of acute myocardial infarction (AMI). This interval also corresponds to the average time between AMI and rupture in patients developing cardiogenic shock. ${ }^{4}$ Operation was completed with associated saphenous bypass grafting to the circumflex territory, and the postoperative course was free of major complications. At the 6-month follow-up, the ejection fraction increased to $48 \%$ and the patient was in New York Heart Association class I.

Previous reports do not specifically pertain to repair performed during the hyperacute phase after AMI, ${ }^{1-3}$ but this approach allows the patch to be anchored to noninfarcted muscle with transmural sutures, whereas nondelayed surgery reduces the obvious impact of prolonged low cardiac output, rendering immediate repair less hazardous. In this respect, the SHOCK trial investigators reported an in-hospital mortality of $87 \%$ among patients with the triad AMIVSR-cardiogenic shock, including patients managed conservatively or judged too sick for surgery, which further suggests a beneficial role of an aggressive strategy.

Conversely, the advantages of left ventricular free wall juxtaposition, as advocated by the authors, are less clear. AMI extends to the anterolateral free wall to a variable degree, whereas the risks of residual cavity restriction are difficult to predict. The level of the papillary muscles is suggested as the proximal limit for safe free wall juxtaposition. However, the technique has also been applied for posterior VSR in 1 patient. This sounds controversial given that posterior VSR usually relates to AMI in the right coronary territory and involves the posterobasal septum. It is possible that the authors repaired a VSR secondary to AMI in the distal territory of an extensively developed left anterior descending artery (ie, distal to the apex and thus along the inferior interventricular groove) with anteroseptal and distal inferior necrosis.

We fully concur that free wall juxtaposition is useful to ensure a secure patch repair, but the technique is most appealing for right ventricular noninfarcted muscle. This strategy may help to successfully perform VSR repair with a more aggressive timing.

Marco Pocar, MD, PhD
Davide Passolunghi, MD
Francesco Donatelli, MD
Cattedra di Cardiochirurgia
Università degli Studi di Milano
IRCCS MultiMedica
Milano, Italy

\section{References}

1. Gerola LR, Kim HC, Filho AP, Araùjo W, Santos PC, Buffolo E. A new surgical technique for ventricular septal rupture closure after myocardial infarction. $J$ Thorac Cardiovasc Surg. 2007;134:1073-6.

2. Morimoto K, Taniguchi I, Miyasaka S, Aoki T, Kato I, Yamaga T. Infarction exclusion technique with transmural sutures for postinfarction ventricular septal rupture. Ann Thorac Cardiovasc Surg. 2004;10:39-41.

3. Bayezid O, Turkay C, Golbasi I. A modified infarct exclusion technique for repair of postinfarction ventricular septal defect. Tex Heart Inst J. 2005;32:299-302. 